\section{References}

El Chammay, R. \& Ammar, W. (2014) Syrian crisis and mental health reform in Lebanon. Lancet, 384, 494.

Fayyad, J., Karam, E., Farhat, C., et al (2014) Turning Teachers into Educators of Tolerance and Conflict Resolution. US Embassy, Lebanon.

Karam, E. G., Mneimneh, Z. N., Karam, A. N., et al (2006) 12-month prevalence and treatment of mental disorders in Lebanon. Lancet, 367, 1000-1006

Karam, E. G., Mneimneh, Z. N., Dimassi, H., et al (2008) Lifetime prevalence of mental disorders in Lebanon: first onset, treatment, and exposure to war. PLoS Med, 5(4), e61.

Ministry of Public Health (2015) Mental Health and Substance Use-Prevention, Promotion, and Treatment. Situation Analysis and Strategy for Lebanon 2015-2020. Available at http:// www.MoPHMoPHMoPHMoPHMoPHMoPHMoPH.gov.lb/Media/ Documents/Mentalhealthstrategy-english.pdf (accessed 24 March 2016).

Naja, W., Aoun, M., El Khoury, E., et al (2016) Prevalence of depression in Syrian refugees and the influence of religiosity. Comprehensive Psychiatry, 68, 78-85.

Souaiby, L., Kazour, F., Zoghbi, M., et al (2016) Impact of the Syrian crisis on the hospitalization of syrians in a psychiatric setting. Community Mental Health Journal, 52, 499.

World Bank (2014) Lebanon Economic Monitor. Available at http://www.worldbank.org/content/dam/ Worldbank/Feature \% 20 Story/mena/Lebanon/lebanon-IEM-fall-2014.pdf (accessed 3 June 2015).

\title{
SPECIAL PAPER \\ Greece and the refugee crisis: mental health context
}

\author{
George N. Christodoulou' and Mohammed T. Abou-Saleh²
}

${ }^{1}$ Professor Emeritus of Psychiatry, University of Athens Medical School, Greece, email profgchristodoulou@gmail.com

2Professor of Psychiatry, St George's, University of London, UK, email mabousal@ gmail.com
The recent influx of refugees and immigrants to Greece has coincided with the ongoing and deteriorating financial crisis. This situation does not allow the Greek authorities to provide help to the desired extent. Yet, the church, local communities, medical societies and non-governmental organisations are offering good psychosocial support. In parallel with support for refugees it is important to provide support for the citizens of the host country. The rich countries of northern Europe should help the poorer countries of southern Europe cope with the refugees. A number of important declarations on refugee mental health and related issues have been produced recently, including the Anti-war Declaration of Athens.

\section{Historical perspective}

Historically, the Greek people have been exposed to many migration and refugee experiences. It is of interest that one of the denominations of Zeus was $\Xi \varepsilon \dot{v}$ เos Zeus (Hosting Zeus), an indication of the value attached to hosting foreigners. In ancient Greece, as a result of wars between the city states and external enemies, refugee situations were continuously created and the need for hosting refugees was always there.

More recently, in 1922 Greek people in Asia Minor had to leave their homeland and become refugees in mainland Greece as a result of a forced ousting that resulted in the death or migration of at least one million people. Following the Second World War and the subsequent Greek civil war, some people moved north to the then communist countries, while others moved from villages to the cities and a great number emigrated to Australia, Canada and other countries in search of a better future.

This long and painful migration history of the Greek people may explain their sympathetic attitude towards the current wave of refugees.

\section{Recent developments}

After 1989, many immigrants arrived from the north (Albania, Russia, Ukraine, Bulgaria). Since 2008 more have arrived from Africa and Asia (Pakistan, Afghanistan, Iraq, Bangladesh etc.). In 2010 , immigrants constituted $7 \%$ of the total population of Greece. This proportion increased further because of developments in Libya and Tunisia and following the application of the Dublin II Regulation of the European Union, which resulted in the return of a great number of refugees from western Europe back to Greece (Anagnostopoulos et al, 2016). The current wave of refugees comes predominantly from the east (mainly Syria and Afghanistan, through Turkey).

\section{The present situation}

The influx of refugees and immigrants making their way across the Mediterranean to Europe in the last couple of years has been estimated as the biggest since the Second World War. In November 2015, Frontex reported that since the start of that year as many as 710000 refugees had entered Greece, the main gateway to Europe (Frontex, 2015).

The refugees have landed mainly on the islands of Lesvos, Chios, Samos, Leros, Kos, Simi and 
Tilos. According to the International Migration Organization (as reported in the Greek newspaper Kathimerini, 18 May 2016), since the beginning of 2016 up to 15 May that year as many as 155837 immigrants and refugees reached Greece, of whom $44 \%$ were men, $22 \%$ women and $34 \%$ children. There was a dramatic increase in arrivals to Greece, from 34442 in 2014 to 853650 in 2015.

There were about 5000 shipwrecks in 2015, which resulted in the tragic drowning of a great number of refugees. Some 89000 refugees have been rescued by the Greek Coast Guard (Hellenic Coast Guard, 2015) and many others by fishermen, but many have died. Among them a Syrian toddler who drowned in the Aegean Sea and who was photographed in a coast in Asia Minor produced great regret and motivated people in Europe to act but this did not last long.

Landing on a Greek island is not the end of the story. The majority of immigrants and refugees do not want to stay in Greece. The country is in the middle of a serious financial crisis and opportunities for employment are practically non-existent. Many refugees have relatives in western Europe and they want to join them. This was relatively easily achieved in the past but, more recently, following the barriers set by many countries, notably FYROM (Former Yugoslav Republic of Macedonia), it has been much more difficult. In Idomeni, a Greek city close to FYROM, about 12000 refugees have established a camp on the railroad and refused to leave, hoping that they will find a way to cross the border. This camp was evacuated in May 2016 but many refugees established another camp nearby.

There are about 50000 refugees in Greece at present and this number keeps increasing. There is still an influx from Turkey and a number of refugees who have managed to cross the border are being 'returned' from FYROM and Bulgaria. The new influx of refugees combined with the economic immigrants already present constitute close to $10 \%$ of the Greek population, a substantial proportion in a country which until recently had a largely homogeneous Greek Orthodox population. This has caused considerable anxiety, which, coupled with occasional assaults by immigrants, has produced xenophobic reactions and has increased the popularity of the extreme right-wing parties, although xenophobic reactions are scarce and by no means comparable to those in some other European countries. There have never been actions of mass violence against, or organised attacks on, refugees.

\section{An unfortunate coincidence}

The recent refugee crisis has coincided with the ongoing and deteriorating financial crisis in Greece. Greece has the highest level of unemployment in the European Union. The morale of the population is low and there are serious mental health consequences (for a review see Christodoulou \& Christodoulou, 2013). This situation does not allow the Greek authorities to provide help to the desired extent. Yet much is being offered by the Greek Orthodox Church, local communities, medical societies, non-governmental organisations (NGOs - notably Médecins Sans Frontières and Doctors of the World) and citizens.

\section{Children}

A large proportion of the current wave of refugees to Greece are children. Among them a significant and increasing number are unaccompanied minors. Requests from this category submitted to the National Centre for Social Solidarity more than doubled from 2013 to 2014 . They were mainly boys (96.8\%), predominantly from Afghanistan (60\%).

As mentioned by Giannakopoulos et al (2016), in a study of 102 unaccompanied minors aged 12-18 who applied for asylum in Germany, mental illness was detected in $13.7 \%$ (Marquardt et al, 2016) and in Malmo in Sweden many more unaccompanied minors received in-patient treatment than did accompanied ones (Ramel et al, 2015).

These children are potentially exposed to great risks, from forced labour to sexual exploitation and abuses of every kind. As mentioned by Anagnostopoulos et al (2016), a national committee for the management of unaccompanied minors has been established by the Greek authorities, and housing, health and psychosocial care are being offered by a network of public services and NGOs, in line with the national child protection legislation.

\section{Mental health consequences}

There is general agreement that refugees are at an elevated risk of psychopathology. This is expected, if one takes into account the stressful life events suffered by practically all refugees. Combined loss of home, status and very often culture, in association with loss of relatives and especially children, and exposure to anxiety and traumatic experiences very often lead to loss of meaning and hope (Fischman, 2008), as well as upheaval of personal identity (Alcock, 2003). Various reports have shown that in addition to their physical, emotional and traumatic experiences, refugees confront poverty, hostility and racism, and experience changes in family functioning and living conditions as well as low social support and isolation (Anagnostopoulos et al, 2016).

A meta-analysis of 181 surveys investigating a total of 81866 refugees found a $30.6 \%$ prevalence rate of post-traumatic stress disorder (PTSD) and $30.8 \%$ of depression (Steel et al, 2009). The detention of immigrants and refugees in camps has been reported to produce further psychological harm and one meta-analysis has shown high levels of anxiety, depression and PTSD (Robjant et al, 2009, mentioned by Taylor-East $e t a l, 2016)$.

For a variety of reasons, mainly associated with the poor finances but also with failure to establish priorities, the mental health of refugees in Greece has not received the attention it deserves. There is clearly a need for quick assessment, with the help of interpreters, and the provision of psychosocial support where needed. 
In parallel with support for the refugees it is important to provide support for the citizens of the host country. There is currently a shift of attention from the unemployed and homeless victims of the Greek economic disaster to the refugees and this is seen by many with resentment.

The attitude of the Greek people towards the current wave of refugees is by and large empathic, although as the number of refugees is increasing there are some indications of impatience, especially when refugees protest in ways that harm the ailing Greek economy, like the blocking of the railroad at Idomeni. Systematic surveys of societal attitudes have not yet been done. Yet it is worrying that research carried out in the past (Economou et al, 2016) has shown a negative attitude towards people in the previous wave of immigration to Greece, focused primarily on dangerousness. It should, however, be pointed out that this finding referred to economic migrants and not to refugees, a category of persons with whom it is easier for Greek people to identify. A more recent poll (reported in Kathimerini on 1 June 2016), carried out on behalf of the Union of Municipalities of Attica, found that $55.7 \%$ of the sample agreed with the reception by Greece of the refugees who reach the country by sea.

The people should be helped to retain their sympathetic approach and governments in the rich parts of Europe should realise that if they do not want to receive refugees they should at least help the poorer countries of southern Europe to cope with the refugees that people in the north are not willing to accept.

Screening for psychopathology is still a neglected issue. Yet the prevalence of psychopathology is expected to be high and it is certainly preferable to treat than not to treat, not only on clinical and humanitarian grounds, but also on cost-effectiveness grounds.

\section{Declarations on refugee mental health}

A number of important declarations on refugee mental health and related issues have been produced recently. We would like to mention the following:

- the World Federation for Mental Health Cairo Declaration on the Mental Health of Refugees, Internally Displaced Persons and Other Populations Affected by Conflict: A Call for Action (2015) (http://www.wfmh.com)

- the European Psychiatric Association's Position Paper on Psychiatric Care of Refugees in Europe (2015) (http://www.europsy.net)

- the World Psychiatric Association Position Statement: Europe, Migrant and Refugee Crisis, in collaboration with the Centre for Applied Research and Evaluation (2016) (http://www. careif.org)

- the World Psychiatric Association-Associacion Psiquiatrica America Latina (WPA-APAL)
Declaration on Refugee and Asylum-Seeker Mental Health (2016) (http://www.wpanet. org/uploads/Position_Statement/WPA-APAL_ Statement.pdf)

- the Position Statement of the European Society of Child and Adolescent Psychiatry on Mental Health of Child and Adolescent Refugees (2016) (http://www.escap.eu/care/position-statement)

- the Anti-war Declaration of Athens, drafted by the Society of Preventive Psychiatry, the Hellenic Psychiatric Association, the Psychiatric Association for Eastern Europe and the Balkans, and the Serbian Psychiatric Association (2016) (http://www.psychiatricprevention.com).

The Anti-war Declaration of Athens is related to the refugee problem because it is based on the assumption that the current wave of refugees and the resulting psychopathology are caused by war in the Middle East. In view of the grave mental health consequences of war, mental health organisations have a right and an obligation to campaign against war. It is encouraging that the Declaration has been co-signed by as many as 100 organisations.

\section{References}

Alcock, M. (2003) Refugee trauma - the assault on meaning. Psychodynamic Practice: Individuals, Groups and Organizations, 9, 291-306.

Anagnostopoulos, D., Triantafyllou, K., Xylouris, G., et al (2016) Migration mental health issues in Europe: the case of Greece. European Child and Adolescent Psychiatry, 25, 119-122.

Christodoulou, N. G. \& Christodoulou, G. N. (2013) Financial crises: impact on mental health and suggested responses. Psychotherapy and Psychosomatics, 82, 279-284.

Economou, M., Charitsi, M., Triantafyllou, E. (2016) In the turmoil of the refugee crisis: the emergence of the 'other' as a threat. Synapsis, 12, 14-17 [in Greek].

Fischman, Y. (2008) Secondary trauma in the legal professions: a clinical perspective. Torture, 18, 107-115.

Frontex (2015) 710,000 migrants entered EU in first nine months of 2015. Available at http://www.hcg.gr/node/11506 2015 (accessed September 2016).

Giannakopoulos, G., Anagnostopoulos, D. \& Lazaratou, H. (2016) Psychological burden of the children of refugees. Synapsis, 12, 18-19 [in Greek].

Hellenic Coast Guard (2015) Unicef awards Greek Coast Guard. Available at http://www.hcg.gr/node/11506 (accessed September 2016).

Marquardt, L., Kramer, A., Fischer, F., et al (2016) Health status and disease burden of unaccompanied asylum-seeking adolescents in Bielefeld, Germany: cross-sectional pilot study. Tropical Medicine and International Health, 21, 210-218.

Ramel, B., Taljemark, J., Lindgren, A., et al (2015)

Overrepresentation of unaccompanied refugee minors in inpatient psychiatric care. Springerplus, 4, 131.

Robjant, K., Hassan, R. \& Katona, C. (2009) Mental health implications of detaining asylum seekers: systematic review. British Journal of Psychiatry, 194, 306-321.

Steel, Z., Chey, T., Silove, D., et al (2009) Association of torture and other potentially traumatic events with mental health outcomes among populations exposed to mass conflict and displacement: a systematic review and meta-analysis. JAMA, 302, 537-549.

Taylor-East, R., Rossi, A., Carnana, J., et al (2016) The mental health services for detained asylum seekers in Malta. BJPsych International, 13, 32-35. 